\title{
Entry Facilitation by Environmental Groups
}

\author{
Allard van der Made • Lambert Schoonbeek
}

Received: 28 September 2007 / Accepted: 24 September 2008 / Published online: 15 October 2008

(C) The Author(s) 2008. This article is published with open access at Springerlink.com

\begin{abstract}
We consider a model of vertical product differentiation where consumers care about the environmental damage their consumption causes. An environmental group is capable of increasing consumers' environmental concern via a costly campaign. We show that the prospect of such a campaign can induce entry by a firm that is able to employ a cleaner technology than the one used by the incumbent. We further demonstrate that the subsequent competition can lead to an adverse effect on aggregate pollution, i.e. the decline in average industry pollution per product is offset by the increase in aggregate production.
\end{abstract}

Keywords Entry · Environmental groups $\cdot$ Persuasive advertising · Vertical product differentiation

JEL Classification $\quad \mathrm{D} 40 \cdot \mathrm{L} 31 \cdot \mathrm{M} 37 \cdot \mathrm{Q} 50$

\section{Introduction}

The past few decades we have witnessed a growing influence of environmental groups (EGs) on economic activity (The Economist 2003). EGs can and do affect market outcomes in various ways. An EG can engage in public politics, in which members of a legislative body are encouraged to act in accordance with the EG's goals. Successful lobbying can lead to a change in the institutional setting which might in turn severely impact the behaviour of economic agents. An EG can alternatively aim its efforts directly at producers or consumers. Such efforts include negotiating directly with firms in order to change their production practices, initiating a boycott against polluting firms, informing consumers about the environmental consequences

\footnotetext{
A. van der Made $(\varangle) \cdot$ L. Schoonbeek

Department of Economics and Econometrics, University of Groningen, P.O. Box 800,

Groningen $9700 \mathrm{AV}$, The Netherlands

e-mail: a.van.der.made@rug.nl

L. Schoonbeek

e-mail: 1.schoonbeek@rug.nl
} 
of their consumption decisions, or persuading consumers to alter their consumption choices. The latter type of so-called private politics (Baron 2001) is the focus of the present paper.

One of the instruments of private politics which has proved to be useful to EGs is campaigning. Such campaigning can include various actions aimed at increasing the media coverage of the issue at stake. We consider campaigns of an EG as a kind of advertising. Following the theoretical literature on advertising by firms (Bagwell 2007; Carlton and Perloff 2005), we mention two reasons for engaging in advertisement activities. First, advertising can be used to inform uninformed consumers about the existence and basic characteristics of products. For instance, EGs use television public service announcements to inform uninformed consumers to what extent their consumption choices contribute to global warning. Another role of advertising by an EG is to persuade (informed) consumers to refrain from purchasing damaging goods by increasing the uneasiness or guilt felt by consumers if they purchase these goods. Think of an EG's advertisement against the use of fur showing photographs of seals which are beaten to death. To give a more detailed example, EGs have campaigned against the use of vinyl (PVC) in the manufacturing of a variety of products, including toys, cosmetics, and paint. PVC often contains phthalate additives. There is mounting evidence that these additives pose a threat to human health. Moreover, since phthalates are hardly biodegradable, these risks are not confined to human beings. The Dutch Greenpeace's campaign used images of little children nibbling at a toy containing PVC. ${ }^{1}$ The use of such images is clearly aimed at increasing the level of guilt felt by concerned parents buying toys containing PVC. Our paper deals with such persuasive advertising. ${ }^{2}$ We look in particular at the impact persuasive advertising has on the entry decision of a new firm on a market and subsequently on aggregate industry pollution. To our knowledge, the impact of the presence of an EG on market structure has not yet been investigated in the theoretical literature.

We consider a duopoly model of vertical product differentiation à la Mussa and Rosen (1978) and Wauthy (1996) where products are differentiated with respect to the amount of (observable) pollution their production causes and consumers differ in their level of environmental concern. The model (without an EG) has also been used by Moraga-González and Padrón-Fumero (2002) to study various environmental policies (for related studies see also Arora and Gangopadhyay 1995; Cremer and Thisse 1999; Bansal and Gangopadhyay 2003). The consumers can buy a good from an incumbent firm which employs a given polluting production technology. A second firm contemplates entering the market. If it decides to do so, it is subsequently able to use the latest technology. This given technology is assumed to be less polluting, but more costly than the one used by the incumbent. After the second firm has decided whether or not it enters, an EG can launch a persuasive campaign which highlights the detrimental effects on the environment of the production of the goods. This brings about a decrease in the consumers' willingness to pay for each good. For simplicity, we assume that different consumers are affected in exactly the same way.

In order to analyze the effects of the EG on the market we compare the equilibrium of the above setting with the equilibrium of a benchmark setting in which there is no EG. For fixed prices, the EG's campaign shifts demand from the old product to the new one. However, since prices adjust to the new circumstances, the effect of the campaign on the

\footnotetext{
${ }^{1}$ See http://www.greenpeace.nl/campaigns/giftige-stoffen-2/informatie-over-giftige-stoffe/de-stoffen-waarhet-om-gaat/ftalaten (in Dutch).

2 Of course, Greenpeace also provided information to consumers in this campaign. However, we focus on the persuasive aspect. The distinction between informative and persuasive advertising might be hard to make in practice. As argued by Carlton and Perloff (2005, p. 477) a given advertisement might be informative for one consumer but persuasive for another consumer. However, it is useful to make this distinction sharply in theoretical discussions.
} 
profit of the new firm is a priori ambiguous. We provide conditions which ensure that if the new firm does enter in the benchmark case, it will a forteriori enter in the EG setting. More interestingly, we show that there exist situations where the EG induces entry by the new firm. That is, the cleaner firm does not enter the market if no EG is present, but it does enter if an EG is present and engages in persuasive advertising. We further derive the counterintuitive finding that in the latter case, the presence of environmental activism might lead to higher aggregate (industry) pollution. In other words, although a considerable part of the consumer population buys a cleaner product in the EG setting, this pollution-reducing effect is offset by the considerable increase in total sales which is caused by the competition resulting from the EG's very presence. In sum, the prospect of campaigning by an EG can attract more environmentally friendly firms. However, the ensuing competition might lead to an increase in aggregate pollution compared to situations in which the possibility of EG campaigning is absent. In the context of our PVC-example, the above results mean that the prospect of a campaign might invite a cleaner toy manufacturer to enter the market. This in turn might lead to an increase of the aggregate pollution caused by the toys industry.

Moraga-González and Padrón-Fumero (2002) also find adverse effects regarding pollution caused by increased competition in their duopoly model with polluting firms. We stress that the mechanisms which are at work in their analysis differ from the ones explored by us. First, in their model there is neither an EG nor the possibility of entry, i.e. the duopoly market structure is exogenous. Second, in Moraga-González and Padrón-Fumero (2002) firms alter their technology choices in response to environmental regulation. Some regulations, most notable unit emission standards, bring about a reduction in the distance between the chosen technologies compared to the no-regulation benchmark technologies. This reduction intensifies competition and leads consequently to increased sales and hence an increase in aggregate pollution. In our setting, however, firms cannot choose their production technologies. In our model the intensification of competition and the resulting adverse effect on aggregate pollution is caused by entry.

Our analysis is related to different strands of literature. First, we model persuasive advertising as a device which directly affects consumers' preferences. This method is predominant in the literature on persuasive advertising by firms in models with vertical and/or horizontal product differentiation (see e.g. von der Fehr and Stevik 1998; Bloch and Manceau 1999; Tremblay and Martin-Filho 2001; Tremblay and Polasky 2002). Second, a few papers have studied entry decisions in standard models with vertical product differentiation (without an EG) where qualities are treated endogenously (see e.g. Donnenfeld and Weber 1992, 1995; Lutz 1997). For reasons of analytical tractability, we must focus on exogenous qualities. Third, our analysis is related to a small but growing literature on the impact of EGs, or more generally, non-governmental organizations, on market outcomes. We mention Heijnen and Schoonbeek (2008), which also considers a model in which an EG can launch a persuasive campaign aimed at influencing consumers' environmental consciousness. In particular, the latter study considers a monopolistic firm that has to choose a production technology, where available technologies differ in the level of pollution they cause. It turns out that the mere threat of the EG's campaign might discipline the monopolist in the most effective way to select a clean production technology. We further mention studies of the effects of EGs on voluntary pollution abatement by firms to avoid government regulation (Maxwell et al. 2000), the transmission of information on environmental product quality via signalling when this quality is not observable by consumers (Feddersen and Gilligan 2001; Heijnen 2007), the governmental permission given to a firm to undertake a polluting project (Liston-Heyes 2001), and the behaviour of polluting firms under the pressure of a consumer boycott (Baron 2001; Innes 2006). Lastly, one could also envisage an EG engaging in informative advertising 
in the present setting. We examine this possibility using a variant of a model by Stivers and Tremblay (2005) who look at informative advertising by firms aimed at reducing consumers' search costs. We find that the EG refrains from such advertising, furthering our motivation of the use of persuasive advertising.

The remainder of this paper is organized as follows. Section 2 introduces the model. Sections 3 and 4 present, respectively, the equilibrium outcomes of the model without EG and with EG. Section 5 compares both settings. We discuss some limitations of the model in Sect. 6. Section 7 concludes. Proofs are in the appendix.

\section{The Model}

We consider a market where products are differentiated with respect to the amount of (observable) pollution their production causes. The demand side consists of a unit mass of consumers who differ in their level of environmental concern. Specifically, a consumer indexed $\theta$ derives the following utility from buying a product which has caused $e$ units of pollution at a price $p$ :

$$
U_{\theta}=V-\theta e-p,
$$

where $V>0$ is the gross willingness to pay for the good. Each consumer either buys one unit of the product or refrains from buying. A consumer derives zero utility from the latter option. $\theta$ is uniformly distributed on an interval $[0, \bar{\theta}]$, where $\bar{\theta}$ signifies the dispersion of marginal disutility of pollution in the population of consumers. ${ }^{3}$ A sole incumbent firm, firm 1 , is active on the market using a given production technology which contaminates the environment by $e_{1}>0$ units per product. The nonnegative marginal costs of production associated with this technology, $c_{1}<V$, are constant. One easily sees that firm 1 maximizes profits by charging $p_{1}^{m}=\frac{V+c_{1}}{2}$ per product. Total sales amount to $q_{1}^{m}=\frac{V-c_{1}}{2 \bar{\theta} e_{1}}$ and total pollution equals

$$
D^{m}=\frac{V-c_{1}}{2 \bar{\theta}}
$$

in this monopoly situation.

A potential entrant, firm 2, contemplates entering the market. If it decides to enter, it is able to employ a given production technology $e_{2}>0$ which is cleaner than $e_{1}$, i.e. $e_{2}<e_{1}{ }^{4}$ However, using a cleaner technology comes at a cost: the constant marginal costs of firm $2, c_{2}$, exceed those of its competitor, i.e. $c_{2}>c_{1}$. Firm 2 only enters if it can make strictly positive profits. We assume that the pair $(V, \bar{\theta})$ is such that the market is never fully covered in equilibrium, i.e. consumer $\bar{\theta}$, the consumer who cares the most about the environment, refrains from buying in equilibrium. This is common practice in the literature, see for example Moraga-González and Padrón-Fumero (2002). We return to this assumption in due course. Moreover, we also assume that firm 2 could make positive profits if firm 1 were not active on the market, i.e. $c_{2}<V$.

Below we study the entry decision of firm 2 in two settings. The benchmark setting consists of two stages. In the first stage firm 2 decides whether or not it enters the market. In the second

\footnotetext{
3 Since individual consumers have zero mass, we can without loss of generality omit the negative externality arising from aggregate pollution from (1). One can alternatively interpret the model as pertaining to situations in which only privately incurred damages affect utility. See also Cremer and Thisse (1999) for a discussion of the use of vertical product differentiation models to model environmental externalities.

4 To economize on space, we identify production technologies with the associated amount of pollution per product.
} 
stage the firms engage in price competition if both firms are active. Firm 1 opts for $p_{1}^{m}$ if it does not face competition in this stage.

The second setting is more complex: in addition to two firms and consumers, it also contains an environmental group (EG). This EG is capable of increasing consumers' environmental consciousness via a costly campaign. We assume that such a campaign causes consumer $\theta$ 's utility derived from buying product $i$ at a price $p_{i}$ to change to:

$$
\hat{U}_{\theta}(i, x)=V-e_{i}\left(\theta+x f\left(e_{i}, e_{j}\right)\right)-p_{i},
$$

where $x \geq 0$ denotes the size of the campaign, $f\left(e_{i}, e_{j}\right)$ is a nonnegative continuous function which (weakly) increases in $e_{i}$, and $i, j \in\{1,2\}$ with $j \neq i$. For the sake of mathematical tractability we assume that each consumer is affected in the same way by the EG's campaign, i.e. $f$ does not depend on $\theta .5$ Notice from (3) that for product $i$, the EG's campaign increases a consumer's initial marginal disutility of pollution $\theta$ with the product of the campaign's size $x$ and the term $f\left(e_{i}, e_{j}\right)$. Because $f\left(e_{i}, e_{j}\right)$ increases in $e_{i}$, the EG's impact on the disutility of pollution derived from buying product $i$ increases in the amount of pollution that good has caused. If firm $i$ is a monopolist, then the EG increases the initial marginal disutility with $x f\left(e_{i}, 0\right)$, where $f\left(e_{i}, 0\right)$ is assumed to be strictly positive as long as $e_{i}>0$.

We further assume that $e_{1} f\left(e_{1}, e_{2}\right)>e_{2} f\left(e_{2}, e_{1}\right)$. Since $e_{i} f\left(e_{i}, e_{j}\right)$ represents the marginal effect of the campaign's size $x$ on each consumer's utility of product $i$, this assumption means that this marginal effect is largest for the dirtier product, implying that the campaign of the EG reinforces the degree of vertical product differentiation. In other words, the campaign increases the perceived saliency of the differences in environmental quality of the two products. This is best understood by looking at some examples. If $f\left(e_{i}, e_{j}\right)=e_{i}$, then the campaign merely emphasizes the amount of pollution caused by the goods. Note that in this specification, the function does not depend on the pollution caused by the other product. Another interesting functional specification is $f\left(e_{i}, e_{j}\right)=\max \left\{0, e_{i}-e_{j}\right\}$, where the EG only tries to persuade consumers not to buy the dirtier product by emphasizing the difference in pollution. Finally, the EG's campaign simply increases each consumer's marginal disutility of pollution by a constant if $f\left(e_{1}, e_{2}\right)=f\left(e_{2}, e_{1}\right)$ is constant.

The objective of the EG is to minimize the aggregate pollution plus the costs associated with its campaign. These costs amount to $\frac{s}{2} x^{2}$, where $s$ captures the productivity of advertising. The problem of the EG therefore reads:

$$
\min _{x} G(x)=\min _{x}\left(e_{1} q_{1}+e_{2} q_{2}+\frac{s}{2} x^{2}\right),
$$

where $q_{i}$ is the quantity sold by firm $i, i \in\{1,2\}$. Note that $q_{2}=0$ if firm 2 does not enter the market. The timing in the setting with an EG is as follows. In the first stage firm 2 decides whether or not to enter. In the next stage the EG sets $x$ and executes its campaign. In the last stage the firms compete in prices if firm 2 has entered. If firm 1 does not face any competition,

5 One could argue that consumers with different $\theta$ 's need not be affected in the same way by the campaign. For instance, one might think that consumers with a large $\theta$ are more susceptible to the EG's message. Then $f$ would be an increasing function of $\theta$. One could alternatively justify $f$ to be decreasing in $\theta$ by pointing out that it is easier to increase the environmental awareness of consumers who lack this trait than to increase even further the environmental awareness of consumers who are already environmentally aware. An alternative to (3) which encompasses both views is

$$
\tilde{U}_{\theta}(i, x)=V-e_{i}\left(\theta+x f\left(e_{i}, e_{j}, \theta\right)\right)-p_{i}
$$

Unfortunately, our calculations reveal that one cannot derive explicit expressions of the EG's optimal strategy with this specification. This lack renders a comparison of the two settings impossible. We therefore confine attention to the intermediate case in which $f$ does not depend on $\theta$. 
it charges the monopoly price. Note that the equilibrium prices and quantities prevailing in the last stage depend on $x$ in this setting.

The timing of the game reflects the fact that for a firm it is difficult to change its entry decision, while a firm may easily change its price as a response to the campaign of the EG. Our timing corresponds to the standard approach in the industrial organization literature, see e.g. Tirole (1988, chapter 8). Moreover, the timing captures the idea that the threat of a future campaign by an EG plays a role in the entry decision of relatively clean firms. ${ }^{6}$

In the next sections we derive the (subgame-perfect Nash) equilibria of the two games. We focus on conditions which ensure that firm 2 finds it profitable to enter the market. In order to be able to discern the outcomes of the benchmark case from those of the EG case, we superscript variables pertaining to the first setting with a $B$ and variables pertaining to the EG setting with an $E$.

\section{The Benchmark Setting}

In this section we analyze the situation without an EG. Suppose first that firm 2 has chosen to enter the market using the production technology $e_{2}<e_{1}$. The consumer who is indifferent between buying product 1 and buying product 2 has taste parameter $\frac{p_{2}-p_{1}}{e_{1}-e_{2}}$, whereas the consumer who is indifferent between buying product 2 and buying neither product is located at $\frac{V-p_{2}}{e_{2}}$. That is, the market is governed by the following demand equations: ${ }^{7}$

$$
\begin{aligned}
q_{1}^{B} & =\frac{p_{2}-p_{1}}{\bar{\theta}\left(e_{1}-e_{2}\right)} \\
q_{2}^{B} & =\frac{V-p_{2}}{\bar{\theta} e_{2}}-\frac{p_{2}-p_{1}}{\bar{\theta}\left(e_{1}-e_{2}\right)}
\end{aligned}
$$

At the last stage firm $i$ maximizes its profit, $\pi_{i}=\left(p_{i}-c_{i}\right) q_{i}$, by setting $p_{i}, i \in\{1,2\}$. The corresponding first-order conditions (FOCs) give the equilibrium prices:

$$
\begin{aligned}
& p_{1}^{B *}=\frac{V\left(e_{1}-e_{2}\right)+2 c_{1} e_{1}+c_{2} e_{1}}{4 e_{1}-e_{2}} \\
& p_{2}^{B *}=\frac{2 V\left(e_{1}-e_{2}\right)+2 c_{2} e_{1}+c_{1} e_{2}}{4 e_{1}-e_{2}}
\end{aligned}
$$

The firms are able to sell the following equilibrium quantities at these prices:

$$
\begin{aligned}
q_{1}^{B *} & =\frac{V\left(e_{1}-e_{2}\right)+c_{2} e_{1}+c_{1} e_{2}-2 c_{1} e_{1}}{\bar{\theta}\left(4 e_{1}-e_{2}\right)\left(e_{1}-e_{2}\right)} \\
q_{2}^{B *} & =\frac{2 V e_{1}\left(e_{1}-e_{2}\right)+e_{1}\left(c_{1} e_{2}+c_{2} e_{2}-2 c_{2} e_{1}\right)}{\bar{\theta} e_{2}\left(4 e_{1}-e_{2}\right)\left(e_{1}-e_{2}\right)}
\end{aligned}
$$

\footnotetext{
${ }^{6}$ It is not difficult to see that all our results still hold qualitatively in the following, more general game: In the first stage firm 2 decides whether or not to enter. In the second stage nature decides whether or not the EG is present. Both firms know at the start of the game the probability $\beta \in[0,1]$ that the EG will be present. In the third stage the EG, if present, chooses its campaign size. In the last stage the firms compete in prices. We only look at the case $\beta=1$ for notational convenience.

${ }^{7}$ Provided $q_{1}^{B}, q_{2}^{B} \in[0,1]$. One easily checks that all equilibrium quantities we mention are between zero and one.
} 
Notice that total sales would amount to $\frac{\left(2 e_{1}+e_{2}\right) V}{\bar{\theta} e_{2}\left(4 e_{1}-e_{2}\right)}$ in the absence of marginal costs. The latter expression clearly exceeds $q_{1}^{B *}+q_{2}^{B *}$ for every pair $\left(c_{1}, c_{2}\right)$. Thus, to ensure that the market is never fully covered in equilibrium, we impose:

$$
\frac{V}{\bar{\theta}}<\frac{e_{2}\left(4 e_{1}-e_{2}\right)}{2 e_{1}+e_{2}}
$$

The equilibrium profits of the entrant, $\pi_{2}^{B *}$, can be expressed as:

$$
\pi_{2}^{B^{*}}=\frac{\left(e_{1}-e_{2}\right) \bar{\theta} e_{2}}{e_{1}}\left(q_{2}^{B *}\right)^{2}
$$

Clearly, firm 2 decides to enter if and only if $q_{2}^{B *}>0$, or, equivalently:

$$
\frac{e_{1}}{e_{2}}>\frac{\left(V-c_{1}\right)+\left(V-c_{2}\right)}{2\left(V-c_{2}\right)}
$$

This condition has a clear interpretation: the pollution per unit product of good 1 relative to the pollution per unit product of good 2 , that is the relative quality of product $2\left(\right.$ i.e. $\left.\left(\frac{1}{e_{2}}\right) /\left(\frac{1}{e_{1}}\right)\right)$, should be large enough. If (10) holds, then both firms are active ${ }^{8}$ and the industry pollutes the environment by the following amount:

$$
D^{B *}=\frac{\left(3 V-2 c_{1}-c_{2}\right) e_{1}}{\bar{\theta}\left(4 e_{1}-e_{2}\right)}
$$

If (10) fails to hold, then firm 1 is able to extract monopoly rents. The associated aggregate pollution can be found in (2).

\section{The EG Setting}

In this section we investigate the situation with an EG. For notational simplicity, we use the abbreviations $\phi_{1} \equiv e_{1} f\left(e_{1}, e_{2}\right)$ and $\phi_{2} \equiv e_{2} f\left(e_{2}, e_{1}\right)$. Note that by assumption $\phi_{1}>\phi_{2}$.

We start with the case where firm 2 has chosen to enter using the technology $e_{2}$. In the last stage the firms engage in Bertrand competition knowing that consumer $\theta$ bases his consumption decision on (3). The demand system associated with this utility function is:

$$
\begin{aligned}
q_{1}^{E} & =\frac{p_{2}-p_{1}}{\bar{\theta}\left(e_{1}-e_{2}\right)}-\frac{x\left(\phi_{1}-\phi_{2}\right)}{\bar{\theta}\left(e_{1}-e_{2}\right)} \\
q_{2}^{E} & =\frac{V-p_{2}-x \phi_{2}}{\bar{\theta} e_{2}}-\frac{p_{2}-p_{1}}{\bar{\theta}\left(e_{1}-e_{2}\right)}+\frac{x\left(\phi_{1}-\phi_{2}\right)}{\bar{\theta}\left(e_{1}-e_{2}\right)}
\end{aligned}
$$

Thus, keeping prices fixed, demand for the dirtier product decreases, whereas demand for the cleaner product goes up due to the EG's campaign. Hence, ceteris paribus the campaign decreases product 1's relative attractiveness.

Solving the FOCs associated with profit maximization in the last stage gives us the equilibrium prices as a function of $x$ :

$$
\begin{aligned}
& p_{1}^{E *}(x)=\frac{V\left(e_{1}-e_{2}\right)+c_{2} e_{1}+2 c_{1} e_{1}-x\left(e_{1}-e_{2}\right) \phi_{2}-x\left(2 e_{1}-e_{2}\right)\left(\phi_{1}-\phi_{2}\right)}{4 e_{1}-e_{2}} \\
& p_{2}^{E *}(x)=\frac{2 V\left(e_{1}-e_{2}\right)+2 c_{2} e_{1}+c_{1} e_{2}-2 x\left(e_{1}-e_{2}\right) \phi_{2}+x e_{2}\left(\phi_{1}-\phi_{2}\right)}{4 e_{1}-e_{2}}
\end{aligned}
$$

8 Observe that $V\left(e_{1}-e_{2}\right)+c_{2} e_{1}+c_{1} e_{2}-2 c_{1} e_{1}>\left(e_{1}-e_{2}\right)\left(c_{2}-c_{1}\right)+e_{1}\left(c_{2}-c_{1}\right)>0$. This ensures that $q_{1}^{B *}>0$. 
Comparing these prices with the equilibrium prices (6) of the benchmark case, we see that a campaign of the EG will lead to a lower equilibrium price of good 1 (since $x$ will be positive in equilibrium). The effect on the equilibrium price of good 2 is ambiguous. One can verify that in the EG setting firm 2 will charge a higher price in equilibrium if and only if $e_{2}\left(\phi_{1}+\phi_{2}\right)>2 e_{1} \phi_{2}$, or, equivalently:

$$
e_{1} f\left(e_{1}, e_{2}\right)+e_{2} f\left(e_{2}, e_{1}\right)>2 e_{1} f\left(e_{2}, e_{1}\right)
$$

Note that condition (14) is always satisfied if $f\left(e_{1}, e_{2}\right)>0$ and $f\left(e_{2}, e_{1}\right)=0$. If $f\left(e_{2}, e_{1}\right)>$ 0 , then this condition can be rewritten as

$$
\frac{e_{1} f\left(e_{1}, e_{2}\right)}{e_{2} f\left(e_{2}, e_{1}\right)}>2\left(\frac{e_{1}}{e_{2}}\right)-1
$$

Recall that $e_{i} f\left(e_{i}, e_{j}\right)$ represents the marginal effect of the size of the EG's campaign on each consumer's utility of product $i$. Hence, (15) articulates the basic intuition that the marginal effect of the campaign's size on the utility associated with product 1 relative to that of product 2 should be large enough in order to induce an equilibrium price increase of good 2 . We finally notice that condition (14) is satisfied in two of the special cases discussed in Sect. 2, namely where $f\left(e_{i}, e_{j}\right)=e_{i}$ or $f\left(e_{i}, e_{j}\right)=\max \left\{0, e_{i}-e_{j}\right\}$. On the other hand, the condition is not satisfied if $f\left(e_{1}, e_{2}\right)=f\left(e_{2}, e_{1}\right)$ is constant.

Substituting (13) in (12) yields the equilibrium quantities as a function of $x$ :

$$
\begin{aligned}
q_{1}^{E *}(x) & =\frac{V\left(e_{1}-e_{2}\right)+c_{2} e_{1}+c_{1} e_{2}-2 c_{1} e_{1}-x\left(e_{1}-e_{2}\right) \phi_{2}-x\left(2 e_{1}-e_{2}\right)\left(\phi_{1}-\phi_{2}\right)}{\bar{\theta}\left(4 e_{1}-e_{2}\right)\left(e_{1}-e_{2}\right)} \\
q_{2}^{E *}(x) & =\frac{2 V e_{1}\left(e_{1}-e_{2}\right)+e_{1}\left(c_{1} e_{2}+c_{2} e_{2}-2 c_{2} e_{1}\right)-x e_{1}\left(2 e_{1}-e_{2}\right) \phi_{2}+x e_{1} e_{2} \phi_{1}}{\bar{\theta} e_{2}\left(4 e_{1}-e_{2}\right)\left(e_{1}-e_{2}\right)}
\end{aligned}
$$

Comparing these quantities with the equilibrium quantities (7) of the benchmark duopoly case, it follows that the EG's campaign will always decrease the (stage three) equilibrium quantity of product 1 . However, the EG's effect on the equilibrium quantity of good 2 is ambiguous. It will increase if and only if condition (14) is satisfied.

We now move to the stage where the EG makes its decision. Aggregate pollution, $D=$ $e_{1} q_{1}+e_{2} q_{2}$, evaluated at the quantities (16) equals:

$$
D^{E *}(x)=\frac{3 V e_{1}-2 c_{1} e_{1}-c_{2} e_{1}-x e_{1} \phi_{2}-2 x e_{1} \phi_{1}}{\bar{\theta}\left(4 e_{1}-e_{2}\right)}
$$

The EG chooses $x$ to minimize $D^{E^{*}}(x)$ plus its costs of campaigning, $\frac{s}{2} x^{2}$. Using the FOC we find the equilibrium size of the campaign:

$$
x^{*}=\frac{e_{1}\left(2 \phi_{1}+\phi_{2}\right)}{s \bar{\theta}\left(4 e_{1}-e_{2}\right)}>0
$$

Combining the expression for $x^{*}$ with (17) gives the equilibrium aggregate pollution:

$$
D^{E *}=\frac{\left(3 V-2 c_{1}-c_{2}\right) e_{1}}{\bar{\theta}\left(4 e_{1}-e_{2}\right)}-\frac{e_{1}^{2}\left(2 \phi_{1}+\phi_{2}\right)^{2}}{s \bar{\theta}^{2}\left(4 e_{1}-e_{2}\right)^{2}}
$$

Substituting $x^{*}$ in (13) and (16), respectively, gives the equilibrium prices $p_{1}^{E *}$ and $p_{2}^{E *}$, and the equilibrium quantities $q_{1}^{E *}$ and $q_{2}^{E *}$. 
Next, consider the stage where firm 2 decides whether or not to enter. Using the fact that we can express firm 2's equilibrium profits as

$$
\pi_{2}^{E *}=\frac{\left(e_{1}-e_{2}\right) \bar{\theta} e_{2}}{e_{1}}\left(q_{2}^{E *}\right)^{2},
$$

we see that firm 2 opts for entry in the EG setting if $q_{2}^{E *}>0$, or, equivalently:

$$
\frac{e_{1}}{e_{2}}>\frac{\left(V-c_{1}\right)+\left(V-c_{2}\right)}{2\left(V-c_{2}\right)}-\frac{x^{*}\left(e_{2}\left(\phi_{1}+\phi_{2}\right)-2 e_{1} \phi_{2}\right)}{2 e_{1}\left(V-c_{2}\right)}
$$

Hence, like in the benchmark setting, firm 2 enters if the relative quality of good $2\left(\left(\frac{1}{e_{2}}\right) /\left(\frac{1}{e_{1}}\right)\right)$ is large enough.

Firm 1 decides to remain active on the market if and only if either (21) does not hold or $q_{1}^{E *}>0$. Note that $q_{1}^{E *}>0$ precisely if:

$$
\frac{e_{1}}{e_{2}}>\frac{\left(V-c_{1}\right)}{2\left(V-c_{1}\right)-\left(V-c_{2}\right)}+\frac{x^{*}\left(\left(2 e_{1}-e_{2}\right) \phi_{1}-e_{1} \phi_{2}\right)}{2 e_{2}\left(V-c_{1}\right)-e_{2}\left(V-c_{2}\right)}
$$

Contrary to the benchmark setting, firm 1 now only remains active if the relative quality of good 2 takes on intermediate values.

A monopoly equilibrium arises if either of the above conditions (21) and (22) does not hold. If, for instance, (21) does not hold, then firm 1 remains a monopolist. In this monopolistic equilibrium firm 1 charges $p_{1}^{E m}=\frac{V+c_{1}-x^{m} \psi_{1}}{2}$, where $x_{1}^{m}=\frac{\psi_{1}}{2 s \bar{\theta}}$ is the optimal choice of the EG and $\psi_{1} \equiv e_{1} f\left(e_{1}, 0\right)$. Total pollution then equals:

$$
D^{E m}=\frac{2 s \bar{\theta}\left(V-c_{1}\right)-\psi_{1}^{2}}{4 s \bar{\theta}^{2}}
$$

Similar expressions can be obtained for the situation in which firm 2 becomes the monopolist. This occurs if (22) fails to hold.

\section{Comparison of the Settings}

We will compare the entry decision of firm 2 in the settings with and without EG. Recall that we only consider situations in which the market is never fully covered, i.e. we assume that (8) is always fulfilled. We observe that firm 2's profits in the EG setting exceed the profits in the benchmark setting if and only if condition (14) is satisfied. Hence, in case firm 2 enters the market in the benchmark setting, i.e. condition (10) is satisfied, then if (14) holds, firm 2 enters a forteriori in the EG setting. In other words, if condition (14) is fulfilled, then the EG facilitates entry of firm 2. More interestingly, it is also possible that firm 2 does enter if the EG is present, but refrains from entry in the benchmark setting. If so, we say that the EG induces entry of firm 2. Using (10), (21), and (22), we see that this only happens if:

$$
\frac{\left(V-c_{1}\right)+\left(V-c_{2}\right)}{2\left(V-c_{2}\right)}-\frac{x^{*}\left(e_{2}\left(\phi_{1}+\phi_{2}\right)-2 e_{1} \phi_{2}\right)}{2 e_{1}\left(V-c_{2}\right)}<\frac{e_{1}}{e_{2}} \leq \frac{\left(V-c_{1}\right)+\left(V-c_{2}\right)}{2\left(V-c_{2}\right)}
$$

or

$$
\begin{aligned}
\frac{e_{1}}{e_{2}} \leq \min \left\{\frac{\left(V-c_{1}\right)}{2\left(V-c_{1}\right)-\left(V-c_{2}\right)}+\frac{x^{*}\left(\left(2 e_{1}-e_{2}\right) \phi_{1}-e_{1} \phi_{2}\right)}{2 e_{2}\left(V-c_{1}\right)-e_{2}\left(V-c_{2}\right)},\right. \\
\left.\frac{\left(V-c_{1}\right)+\left(V-c_{2}\right)}{2\left(V-c_{2}\right)}\right\}
\end{aligned}
$$


Condition (24a) presents bounds on the relative quality of product 2 such that firm 2 does enter in the EG setting, but does not enter in the benchmark setting conditional on firm 1 remaining active. If (24b) holds, then the EG's campaign enables firm 2 to monopolize the market, whereas, in the absence of the EG, it would not even decide to enter the market. Notice that (24a) can only be satisfied if (14) holds. We now present our first proposition.

Proposition 1 There exist situations where the campaign of the EG induces entry of firm 2. These situations occur if and only if (24) holds.

Proof See the appendix.

Hence, we see that there indeed exist parameter configurations such that firm 2 does not enter the market in the absence of the EG, but does enter if the EG is present.

We now compare the aggregate pollution of the various equilibria that can emerge. It is straightforward to infer from (2), (11), (19), and (23) that $D^{m}>D^{E m}, D^{B *}>D^{E *}$, and $D^{m}<D^{B *}$. One can gather some intuitive insights from these inequalities. First, the EG's interference reduces aggregate pollution if the same market structure emerges in the two settings. Second, aggregate pollution in the benchmark setting is highest if a duopoly outcome prevails. We finally assess the sign of $D^{E *}-D^{m}$. The quantity $D^{E *}-D^{m}$ is the difference in aggregate pollution between the two settings if firm 2 only enters in the EG setting and firm 1 remains active, i.e. both (22) and (24a) hold. We show that such parameter configurations exist and, surprisingly, that the equilibrium aggregate pollution can be higher in the EG setting than in the benchmark setting in this parameter range. We present these results in the next proposition.

Proposition 2 There exist situations in which the presence of the EG (i) induces entry by firm 2 while firm 1 remains active on the market, and (ii) by doing so increases aggregate pollution, i.e. $D^{E^{*}}>D^{m}$. These situations occur if both (22) and (24a) hold and, moreover, $s$ is sufficiently large.

Proof See the appendix.

The intuition behind this result is as follows. The prospect of the EG's campaign makes the market more attractive for firm 2. This induces entry and creates price competition. Aggregate equilibrium sales exceed the sales in the monopoly equilibrium which would prevail in the absence of the EG. However, average industry pollution per product goes down because the campaign shifts demand towards the cleaner product. Yet, this decrease in average pollution is small compared to the increase in aggregate sales if the EG's cost parameter $s$ is large enough. Since $x^{*}$ becomes small as $s$ grows, we see that for large $s$, the part $-x^{*} e_{i} f\left(e_{i}, e_{j}\right)$ in the utility function (3) does impact the equilibrium market structure, but it is small compared to the part $V-\theta e_{i}$. In other words, if the EG's cost parameter $s$ is large enough, then the size of the EG's campaign is small and it does not substantially alter consumers' utility. The small shift in demand is sufficient to lure the cleaner producer into the market, but the resulting decrease in average industry pollution is more than offset by the increase in aggregate sales which is a consequence of the ensuing competition.

Remark 1 Proposition 1 and Proposition 2 carry through if the assumption of unequal marginal costs, $0 \leq c_{1}<c_{2}$, is replaced by assuming equal marginal costs, $c_{1}=c_{2} \equiv c \geq 0$, plus fixed entry costs $F>0$ for firm 2. Comparison of (9) and (20) reveals that the EG can induce entry by firm 2 for intermediate values of $F$ and equal marginal costs. Specifically, we have that for $s$ large enough there exists a non-empty range $(\underline{F}, \bar{F})$ such that if $F$ is in 
this range, then firm 2 does not opt for entry if there is no EG (since $F>\underline{F}$ ), but does enter if the EG is present (since $F<\bar{F}$ ), while aggregate pollution increases due to the presence of the EG.

Remark 2 The following alternative advertising mechanism leads to similar conclusions. The EG can use firm-specific campaign efforts $x_{i}$ which lead to a shift in the initial marginal disutility of pollution caused by the production of good $i, i \in\{1,2\}$. Specifically, consumer $\theta$ 's net valuation for product $i$ decreases to

$$
\tilde{U}_{\theta}\left(i, x_{1}, x_{2}\right)=V-e_{i}\left(\theta+x_{i}\right)-p_{i}
$$

if the EG opts for the sizes $\left(x_{1}, x_{2}\right), i \in\{1,2\}$. This specification effectively allows the EG to endogenize its advertising technology. If total advertising costs amount to

$$
\frac{s}{2}\left(x_{1}^{2}+x_{2}^{2}\right)
$$

then the EG chooses

$$
x_{1}^{*}=\frac{2 e_{1}^{2}}{s \bar{\theta}\left(4 e_{1}-e_{2}\right)}, \quad x_{2}^{*}=\frac{e_{1} e_{2}}{s \bar{\theta}\left(4 e_{1}-e_{2}\right)}
$$

in a duopoly equilibrium. It can be shown that these choices lead to entry inducement and that aggregate pollution can go up due to the presence of an EG capable of employing the above advertising mechanism.

\section{Discussion}

In this section we discuss some limitations of our model. Needless to say, we do not claim to allude below to every single shortcoming one could think of.

We do not look at situations in which the firms can engage in (persuasive) advertising. Since $e_{1} f\left(e_{1}, e_{2}\right)>e_{2} f\left(e_{2}, e_{1}\right)$, it might be profitable for firm 2 to use advertising if it has an advertising technology similar to the one employed by the EG at its disposal. One can indeed show that firm 2 engages in such advertising if both (14) holds (advertising results in a higher equilibrium price for good 2) and either (10) holds (firm 2 would also enter in the absence of advertising) or firm 2 can advertise very efficiently (firm 2 has a very low $s$ ). ${ }^{9}$ Alternatively, firm 2 could make donations to the EG to induce the latter to start a campaign. We did not investigate these possibilities in great detail for the following reasons. First, it might be that environmental groups are better able to increase the environmental awareness of consumers than firms are. Persuasive advertising by firm 2 could not be as credible as persuasive advertising by the EG, especially since production of good 2 is also detrimental to the environment. Second, we are mainly interested in the impact of environmental groups on entry decisions. We therefore omit possibilities which would interfere with the relationship between the presence of EGs and market structure.

It would be interesting to study the welfare implications of the EG's interference. However, such an analysis is complicated by the fact that the EG's persuasive advertising alters consumer preferences. Consequently, consumers' surplus and hence welfare changes due to the EG's campaign even if the same economic outcomes prevail as without the campaign. Dixit and Norman (1978) proposed a method to perform welfare analyses in the presence of changes in consumer preferences caused by persuasive advertising. First, compare welfare

${ }_{9}$ Details are available from the authors upon request. 
in the equilibria with and without advertising using in both cases the pre-advertising preferences. Second, compare welfare in the two equilibria using post-advertising preferences. If these two welfare measures move in the same direction, say both increase, then Dixit and Norman conclude that advertising does indeed increase welfare. No final conclusion can be drawn, however, if the two measures do not move in the same direction. Dixit and Norman's procedure has been discussed critically in the literature, see Carlton and Perloff (2005, pp. 483-486).

Clearly, the complexity of the expresssions we have arrived at precludes analytical derivations of welfare implications. We thus calculate welfare numerically taking $f\left(e_{i}, e_{j}\right)=e_{i}$ and focusing on situations where the EG's campaign induces entry. Welfare is defined as the sum of consumers' surplus, aggregate profits, and $G$, the payoff of the EG. ${ }^{10}$ Applying the procedure of Dixit and Norman (1978), it turns out that welfare is unambiguously decreased by the EG's campaign for most parameter values. For example, if $V=8, \bar{\theta}=4, s=4$, $e_{1}=2.4, e_{2}=1.7, c_{1}=0.3, c_{2}=3.8$, then both welfare measures attribute a drop in welfare to the EG's campaign. However, there are also cases where the procedure remains inconclusive. If, for instance, $V=8, \bar{\theta}=4, s=4, e_{1}=2.2, e_{2}=1.9, c_{1}=0.1, c_{2}=2$, then welfare measured using pre-campaign preferences is higher in the equilibrium with EG than in the benchmark equilibrium. However, with post-campaign preferences welfare decreases due to the EG's campaign. We therefore refrain from a detailed welfare analysis.

A welfare analysis would not be hindered by shifts in preferences if the EG engaged in informative advertising instead of persuasive advertising. One could envision two kinds of informative advertising in the present setting. The first one is based on the seminal work of Milgrom and Roberts (1986) on signalling in models of advertising. Applied to our setting it would mean that the firms and the EG are fully informed about the environmental quality of both goods whereas consumers lack this information. The EG attempts to convey something about these qualities to consumers, but the content of its messages need not be truthful. Analysis of the model then amounts to studying signalling equilibria in which the firms and the EG signal environmental qualities by selecting the prices of the goods and the observable expenditures on the campaign, respectively. Clearly, such an analysis is completely different from the analysis we carried out. Heijnen (2007) explores this approach in a model with one firm and an EG. It is challenging to extend his model with a second firm. This is, however, beyond the scope of the present paper.

A second kind of informative advertising deals with search costs. The idea behind this branch of the literature is that it is costly for consumers to obtain a price and/or quality quote for a product. See McMillan and Rothschild (1994) for a concise survey of this literature. Advertising can reduce these search costs. Translated to our setting this would mean that search costs are reduced by the EG's campaign. To fix ideas, suppose that consumers know $e_{1}$, but are unaware of the environmental quality $e_{2}$ of good 2 . Then only environmentally aware consumers who believe $e_{2}$ is low would find it worthwile to visit firm 2. If the EG launches a campaign aimed at informing consumers about $e_{2}$, then consumers can learn $e_{2}$ in a less time-consuming way. Firm 2 consequently attracts more consumers. We checked this idea using a model proposed by Stivers and Tremblay (2005). To arrive at a model similar to the model of Tremblay and Stivers, we replaced $-e_{i} x f\left(e_{i}, e_{j}\right)$ by $\mu_{i}(x)$ in (3). $\mu_{i}(x)$ signifies firm-specific search costs. One can interpret $p_{i}+\mu_{i}(x)$, the price the firm receives plus the search costs incurred by the consumer, as the consumer price of good $i$. The EG's campaign reduces the search costs, i.e. $\mu_{i}^{\prime}(x) \leq 0$ for all $x>0$. Note that in the above story $\mu_{1}(x) \equiv 0$.

10 Since the EG is absent in the benchmark setting, one could argue that $G$ should not be included in the welfare of the benchmark setting. However, because our definition takes into account the same set of actors in both settings, we think that it is more appropriate to include $G$. Note that we take $x \equiv 0$ in the benchmark case. 
Redoing the analysis of Sect. 4, we found that the EG refrains from advertising $\left(x^{*}=0\right)$ for all specifications of $\mu_{1}$ and $\mu_{2} \cdot{ }^{11}$ In other words, the EG never launches a campaign in the equilibrium of the model with search costs. This result can be understood by observing that a reduction in search costs associated with a good always increases each consumer's utility derived from buying that good. In other words, the EG cannot reduce the utility associated with good 1. The EG therefore lacks the power to induce a considerable shift in demand from good 1 to good 2, rendering advertising unprofitable. By contrast, in the model with persuasive advertising the EG is able to reduce good 1's absolute attractiveness. Our result is reminiscent of Stivers and Tremblay's conclusion that firms underprovide advertising aimed at reducing search costs.

\section{Conclusion}

We have looked at the impact persuasive advertising by an EG can have on market structure and aggregate pollution. Our analysis shows that the EG's actions can induce entry of a new firm that produces a cleaner product, but that this need not imply less aggregate pollution. We mention that this counterproductive effect would vanish if ex ante, i.e. before entry of the new firm, the EG were able to commit itself to refraining from engaging in persuasive advertising. However, in the present setting, the potential entrant correctly anticipates that the EG does launch a campaign after the entry stage. In other words, the threat of a campaign by an environmental group attracts relatively clean firms.

Our analysis has a number of limitations. We have discussed the most important ones in the previous section. In particular, we mentioned that firm 2 is not allowed to engage in profitable advertising and the fact that a welfare analysis is hindered by the persuasive nature of the EG's advertising. Another potential shortcoming concerns the fact that we restrict attention to situations with at most two firms. We plan to study extensions which address these limitations in future work.

\section{Appendix}

Proofs

Proof of Proposition 1 It has already been shown that entry inducement occurs precisely if (24) holds. Below we prove that there exist parameter values such that (24a) holds. One can use similar arguments to show that there exist parameter values for which (24b) holds.

Take a function $f\left(e_{i}, e_{j}\right)$ and parameters $\left(V, c_{1}, c_{2}, s\right)$ such that $0 \leq c_{1}<c_{2}<V$ and $s>0$. Choose an arbitrary lower bound $\underline{e}>0$ and an arbitrary upper bound $\bar{e}>0$ for the technologies of the firms and define:

$$
H \equiv\left\{\left(e_{1}, e_{2}\right) \mid \underline{e} \leq e_{2}<e_{1} \leq \bar{e}, \lambda>0\right\},
$$

11 One can show that the derivative with respect to $x$ of $G$ (see (4)) evaluated at the second stage equilibrium values reads

$$
\frac{-e_{1} \mu_{2}^{\prime}(x)-2 e_{1} \mu_{2}^{\prime}(x)}{\bar{\theta}\left(4 e_{1}-e_{2}\right)}+s x
$$

Since $\mu_{i}^{\prime}(x) \leq 0, i=1,2, x^{*}=0$ maximizes the EG's objective. Details are available from the authors upon request. 
where $\lambda \equiv \alpha\left(\phi_{1}+\phi_{2}\right)-2 \phi_{2}$ and $\alpha \equiv \frac{e_{2}}{e_{1}} \in(0,1)$. Note that $\lambda$ is positive if and only if (14) holds. Take $\bar{\theta}>0$ such that (8) holds for all $\left(e_{1}, e_{2}\right) \in H$.

Using $\alpha$, we can rewrite (24a) as:

$$
\frac{\left(V-c_{1}\right)+\left(V-c_{2}\right)-x^{*} \lambda}{2\left(V-c_{2}\right)}<\frac{1}{\alpha} \leq \frac{\left(V-c_{1}\right)+\left(V-c_{2}\right)}{2\left(V-c_{2}\right)},
$$

where

$$
x^{*}=\frac{\left(2 \phi_{1}+\phi_{2}\right)}{s \bar{\theta}(4-\alpha)}
$$

Recall that (A.2) can only hold if condition (14) is satisfied. We now show that we can find parameters $\left(e_{1}, e_{2}\right) \in H$ such that (A.2) is fulfilled. In order to do this, let:

$$
y \equiv \min _{\left(e_{1}, e_{2}\right) \in H} \frac{\left(2 \phi_{1}+\phi_{2}\right)\left(\alpha\left(\phi_{1}+\phi_{2}\right)-2 \phi_{2}\right)}{s \bar{\theta}(4-\alpha)}>0
$$

The above definitions imply that $x^{*} \lambda \geq y$ for all $\left(e_{1}, e_{2}\right) \in H$. Since $\frac{\left(V-c_{1}\right)+\left(V-c_{2}\right)}{2\left(V-c_{2}\right)}>1$, there exist $\left(e_{1}, e_{2}\right) \in H$ such that:

$$
\frac{\left(V-c_{1}\right)+\left(V-c_{2}\right)-y}{2\left(V-c_{2}\right)}<\frac{1}{\alpha} \leq \frac{\left(V-c_{1}\right)+\left(V-c_{2}\right)}{2\left(V-c_{2}\right)}
$$

By the definition of $H$ and $y$, the parameters $V, c_{1}, c_{2}, s, \bar{\theta}, e_{1}$ and $e_{2}$ satisfy a forteriori (A.2), i.e. the $\mathrm{EG}$ induces entry of firm 2.

Proof of Proposition 2 Take a function $f\left(e_{i}, e_{j}\right)$ and parameters $\left(V, c_{1}, c_{2}\right)$ such that $0 \leq$ $c_{1}<c_{2}<V$. Choose an arbitrary lower bound $\underline{e}>0$ and an arbitrary upper bound $\bar{e}>0$ for the technologies of the firms and define:

$$
H \equiv\left\{\left(e_{1}, e_{2}\right) \mid \underline{e} \leq e_{2}<e_{1} \leq \bar{e}, \lambda>0\right\},
$$

where $\lambda \equiv \alpha\left(\phi_{1}+\phi_{2}\right)-2 \phi_{2}$ and $\alpha \equiv \frac{e_{2}}{e_{1}} \in(0,1)$. Note that $\lambda$ is positive if and only if (14) holds. Take $\bar{\theta}>0$ such that (8) holds for all $\left(e_{1}, e_{2}\right) \in H$.

We first show that we can find parameters $\left(e_{1}, e_{2}\right) \in H$ and $s>0$ such that conditions (22) and (24a) hold simultaneously. Using $\alpha$, condition (24a) can be rewritten as:

$$
\frac{\left(V-c_{1}\right)+\left(V-c_{2}\right)-x^{*} \lambda}{2\left(V-c_{2}\right)}<\frac{1}{\alpha} \leq \frac{\left(V-c_{1}\right)+\left(V-c_{2}\right)}{2\left(V-c_{2}\right)},
$$

while (22) reduces to:

$$
\frac{1}{\alpha}>\frac{\left(V-c_{1}\right)+x^{*} \tau}{2\left(V-c_{1}\right)-\left(V-c_{2}\right)},
$$

where

$$
x^{*}=\frac{\left(2 \phi_{1}+\phi_{2}\right)}{s \bar{\theta}(4-\alpha)}
$$

and $\tau \equiv \frac{(2-\alpha) \phi_{1}-\phi_{2}}{\alpha}$. Since $\phi_{1} \geq \phi_{2}, \tau$ is positive. Recall that (A.7) can only hold if condition (14) is satisfied.

Let

$$
z_{1} \equiv \min _{\left(e_{1}, e_{2}\right) \in H} \frac{\left(2 \phi_{1}+\phi_{2}\right)\left(\alpha\left(\phi_{1}+\phi_{2}\right)-2 \phi_{2}\right)}{4-\alpha}>0
$$


and

$$
z_{2} \equiv \max _{\left(e_{1}, e_{2}\right) \in H} \frac{\left(2 \phi_{1}+\phi_{2}\right)\left((2-\alpha) \phi_{1}-\phi_{2}\right)}{\alpha(4-\alpha)}>0
$$

The above definitions imply that

$$
x^{*} \lambda \geq \frac{z_{1}}{s \bar{\theta}} \text { and } x^{*} \tau \leq \frac{z_{2}}{s \bar{\theta}}
$$

for all $\left(e_{1}, e_{2}\right) \in H$ and all $s>0$. Because $V-c_{1}>V-c_{2}>0$, one has:

$$
\frac{\left(V-c_{1}\right)}{2\left(V-c_{1}\right)-\left(V-c_{2}\right)}<\frac{\left(V-c_{1}\right)+\left(V-c_{2}\right)}{2\left(V-c_{2}\right)}
$$

One can therefore find a threshold $S>0$ such that:

$$
\frac{\left(V-c_{1}\right)+\frac{z_{2}}{s \bar{\theta}}}{2\left(V-c_{1}\right)-\left(V-c_{2}\right)}<\frac{\left(V-c_{1}\right)+\left(V-c_{2}\right)}{2\left(V-c_{2}\right)}
$$

if $s>S$. It follows that there exist $\left(e_{1}, e_{2}\right) \in H$ such that both

$$
\frac{1}{\alpha} \in\left(\frac{\left(V-c_{1}\right)+\frac{z_{2}}{s \bar{\theta}}}{2\left(V-c_{1}\right)-\left(V-c_{2}\right)}, \frac{\left(V-c_{1}\right)+\left(V-c_{2}\right)}{2\left(V-c_{2}\right)}\right]
$$

and

$$
\frac{1}{\alpha}>\frac{\left(V-c_{1}\right)+\left(V-c_{2}\right)-\frac{z_{1}}{s \bar{\theta}}}{2\left(V-c_{2}\right)}
$$

if $s>S$. By the definition of $z_{1}$ and $z_{2}$ such combinations of $e_{1}, e_{2}$ and $s$ satisfy a forteriori (A.7) and (A.8), i.e. the EG induces entry by firm 2 and firm 1 remains active.

It remains to show that aggregate pollution increases due to the presence of the EG for some of the above parameter configurations. Now $D^{E^{*}}>D^{m}$ precisely if:

$$
\frac{3 V-2 c_{1}-c_{2}}{\bar{\theta}(4-\alpha)}-\frac{\left(2 \phi_{1}+\phi_{2}\right)^{2}}{s \bar{\theta}^{2}(4-\alpha)^{2}}>\frac{V-c_{1}}{2 \bar{\theta}}
$$

This can be rewritten as:

$$
2\left(V-c_{2}\right)+\alpha\left(V-c_{1}\right)>\frac{2\left(2 \phi_{1}+\phi_{2}\right)^{2}}{s \bar{\theta}(4-\alpha)},
$$

which obviously holds for the parameters $V, c_{1}, c_{2}, \bar{\theta}, e_{1}$ and $e_{2}$ if $s$ is sufficiently large.

Acknowledgements Van der Made acknowledges The Netherlands Organization for Scientific Research (NWO) for financial support. The authors wish to thank Marco Haan, Pim Heijnen, José Luis Moraga-González, Linda Toolsema-Veldman, and seminar participants at the PC2007, especially Hans-Peter Weikard, for useful suggestions. This paper greatly benefited from the comments of two anonymous referees.

Open Access This article is distributed under the terms of the Creative Commons Attribution Noncommercial License which permits any noncommercial use, distribution, and reproduction in any medium, provided the original author(s) and source are credited. 


\section{References}

Arora S, Gangopadhyay S (1995) Toward a theoretical model of voluntary overcompliance. J Econ Behav Organ 28:289-309

Bagwell K (2007) The economic analysis of advertising. In: Armstrong M, Porter R (eds) Handbook of industrial organization, vol. 3. North-Holland, Amsterdam, pp 1701-1844

Bansal S, Gangopadhyay S (2003) Tax/subsidy policies in the presence of environmentally aware consumers. J Environ Econ Manage 45:333-355

Baron D (2001) Private politics, corporate social responsibility, and integrated strategy. J Econ Manage Strategy 10:7-45

Bloch F, Manceau D (1999) Persuasive advertising in Hotelling's model of product differentiation. Int J Ind Organ 17:557-574

Carlton D, Perloff J (2005) Modern industrial organization, 4th edn. Addison Wesley, Boston

Cremer H, Thisse J-F (1999) On the taxation of polluting products in a differentiated industry. Eur Econ Rev 43:575-594

Dixit A, Norman V (1978) Advertising and welfare. Bell J Econ 9:1-17

Donnenfeld S, Weber S (1992) Vertical product differentiation with entry. Int J Ind Organ 10:449-472

Donnenfeld S, Weber S (1995) Limit qualities and entry deterrence. RAND J Econ 26:113-130

Feddersen T, Gilligan T (2001) Saints and markets: activists and the supply of credence goods. J Econ Manage Strategy 10:149-171

Heijnen P (2007) Informative advertising by an environmental group. CenDEF working paper 07-02, University of Amsterdam

Heijnen P, Schoonbeek L (2008) Environmental groups in monopolistic markets. Environ Resour Econ 39:379-396

Innes R (2006) A theory of consumer boycotts under symmetric information and imperfect competition. Econ J 116:355-381

Liston-Heyes C (2001) Setting the stakes in environmental contests. J Environ Econ Manage 41:1-12

Lutz S (1997) Vertical product differentiation and entry deterrence. J Econ 65:79-102

Maxwell J, Lyon T, Hackett S (2000) Self-regulation and social welfare: the political economy of corporate environmentalism. J Law Econ 43:583-617

McMillan J, Rothschild M (1994) Search. In: Aumann R, Hart S (eds) Handbook of game theory, vol. 2. North-Holland, Amsterdam, pp 905-927

Milgrom P, Roberts J (1986) Price and advertising signals of product quality. J Polit Econ 94:796-821

Moraga-González J, Padrón-Fumero N (2002) Environmental policy in a green market. Environ Resour Econ 22:419-447

Mussa M, Rosen S (1978) Monopoly and product quality. J Econ Theory 18:301-317

Stivers A, Tremblay V (2005) Advertising, search costs, and social welfare. Inf Econ Policy 17:317-333

The Economist (2003) Living with the enemy; Non-governmental organisations and business (August 9, 2003)

Tirole J (1988) The theory of industrial organization. The MIT Press, Cambridge

Tremblay J, Martin-Filho C (2001) A model of vertical differentiation, brand loyalty, and persuasive advertising. In: Baye M, Nelson J (eds) Advances in applied microeconomics, vol 10. AI Elsevier, Amsterdam

Tremblay V, Polasky S (2002) Advertising with subjective horizontal and vertical product differentiation. Rev Ind Organ 20:253-265

von der Fehr N-H, Stevik K (1998) Persuasive advertising and product differentiation. South Econ J 65:113126

Wauthy X (1996) Quality choice in models of vertical product differentiation. J Ind Econ 44:345-353 